\title{
Inventário crítico dos dez anos do mestrado em Política Social da Universidade Federal de Mato Grosso
}

\section{Critical inventory of the ten years of the Master's Program in Social Policy at the Federal University of Mato Grosso}

\author{
Leana Oliveira Freitas ${ }^{a}$ \\ (D) https://orcid.org/0000-0001-9477-6560 \\ Bruna Andrade Irineu ${ }^{a}$ \\ (D) https://orcid.org/0000-0003-1158-5000 \\ Josiley Carrijo Rafael ${ }^{a}$ \\ (D) https://orcid.org/ 0000-0002-8639-8114
}

\begin{abstract}
Resumo: $O$ artigo examina os dez anos do PPGPS/UFMT, demarcando, no reconhecimento da pesquisa, seu elemento fundante, resultado da articulação entre graduação e pós-graduação. A política social, como área interdisciplinar, explica a demanda pelo PPGPS por sujeitos de distintas áreas de formação que atuam na docência, pesquisa e no ciclo das políticas públicas, confirmando o significado social do programa na região e a relevância da universidade na sociedade, sobretudo em tempos de retrocessos de direitos.
\end{abstract}

Palavras-chave: Universidade. Pós-graduação. Serviço Social. Política social. UFMT.

\begin{abstract}
This paper examines the ten years of PPGPS/UFMT, demarcating, in the recognition of research, its founding element, the result of the articulation between undergraduate and graduate courses. The Social Policy, as a interdisciplinary area, explains the demand for PPGPS by subjects from different training areas who work in teaching, research and cicle of public policies, confirming the social meaning of the Program in the region and the relevance of the University in society, especially in times of regression in rights.
\end{abstract}

Keywords: University. Post-graduate. Social Work. Social Policy. UFMT. 


\section{Introdução}

propósito de lançar elementos determinantes para a compreensão dos dados e análises que serão apresentados no decorrer deste

artigo, destacamos que a criação da UFMT e do curso de Serviço Social ocorre num contexto da recente história brasileira, sob os ditames da ditadura militar e do Ato Institucional n 5 . O surgimento dessas duas instituições, no contexto da ditadura militar, carece de maior investigação, que possa demonstrar a direção político-pedagógica do curso e de todo o significado da UFMT nos anos de chumbo.

Atualmente, Mato Grosso, cuja área total é de 903.206 km², possui população média de 3,03 milhões de habitantes. Desse total, pouco menos de 1 milhão se concentra na baixada cuiabana, que agrega treze municípios. É nesse contexto populacional que se insere o maior campus da UFMT, em Cuiabá, com oferta de 47 cursos de graduação, correspondentes a 2.929 vagas anuais e com cinquenta programas de pós-graduação. Destes, treze possuem cursos de mestrado e doutorado (acadêmicos), três possuem apenas cursos de doutorado, e 26 somente mestrado.

Expostas as anotações que abrem este artigo, destacamos que nosso objetivo é apresentar um inventário crítico ${ }^{1}$ dos dez anos do mestrado em Política Social da UFMT (PPGPS), com ênfase nas tendências e características que marcam essa década, sua inserção regional e nacional, demonstrando a relevância da universidade na sociedade.

\section{O reconhecimento da pesquisa na articulação entre graduação e pós-graduação: antecedentes da criação do PPGPS/UFMT}

Ao longo do cinquentenário da UFMT e do Departamento de Serviço Social, a graduação expressou projetos profissionais consonantes

1 Em 2019, o termo "inventário" foi utilizado por Iasi, Figueiredo e Neves em A estratégia democrático-popular: um inventário crítico, o qual nos inspirou. Os autores destacam que a terminologia foi tomada de empréstimo do Cadernos do cárcere, v. 3, de Gramsci. 
às características de seus respectivos tempos históricos, seis ao longo desse período. A preocupação em articular formação profissional com a pesquisa e a extensão pode ser identificada no Projeto Político Pedagógico (PPP) de 1985, que indicava diretrizes para a inclusão dessa articulação. Os PPP subsequentes já instituem a pesquisa no espaço acadêmico, inicialmente pela criação de núcleos temáticos de estudos e pesquisas, que vigoraram até a definição das suas linhas que são apresentadas no PPP/2007 (Rafael e Azevedo, 2019). Esse momento demonstra a maturidade intelectual do corpo docente, gerada pela participação nas entidades representativas do Serviço Social (Abess/Abepss e CFESS), e, principalmente, pela qualificação em nível de pós-graduação stricto sensu por parte significativa das docentes nos cursos da UnB, PUC-SP, UFMA, PUC-RJ, UFRJ e PUC-RS. Como decorrência desse processo é que se tem a criação do PPGPS/UFMT, em 2009.

Cabe destacar que a implementação completa das Diretrizes Curriculares da Abepss/1996 só se realizou com a aprovação do PPP/2007. Esse documento, ao tratar sobre a "Política de pesquisa, extensão e pós-graduação", já sinalizava para a "instituição do curso de pós-graduação (especialização/mestrado)” (UFMT, 2007, p. 85), definindo como linhas de pesquisa: 1) Estado, sociedade e Serviço Social; 2) Trabalho, questão social e Serviço Social, sendo posteriormente alteradas no PPC/2010 para: 1) Política social, Estado, direitos e movimentos sociais; 2) Trabalho, questão social e Serviço Social, expressando assim, uma política de pesquisa que articula os projetos pedagógicos da graduação e do mestrado.

O percurso dos dez anos de funcionamento do PPGPS é atravessado por conjunturas distintas, desde o processo de expansão dos programas de pós-graduação no cenário nacional até atual crise da educação superior. Inúmeras e complexas são as constatações que poderíamos sinalizar como consequência da crise estrutural do capital e seu rebatimento na educação, confirmando as análises de Mészáros (2008) sobre o modelo de educação institucionalizada e enraizada na sociabilidade burguesa.

Ao longo desse tempo, porém, não existem precedentes que possam ser comparados com o significado da Emenda Constitucional no 95/2016. 
As universidades amargam o corte de recursos, colocando em xeque o futuro do ensino superior público e gratuito. Recentemente, a proposta de radicalização do empresariamento da educação anunciada pelo Future-se aprofundou ainda mais a restrição orçamentária na educação e na ciência (Leher, 2019). Vários são os episódios que demonstram o processo de destruição da educação, ampliando o que Pinassi (2009) denominou como "metástase do irracionalismo". Na contramão desse processo, o PPGPS tem resistido por meio da produção de conhecimento comprometida com a superação dessa realidade.

\section{A particularidade do PPGPS/UFMT no âmbito da área de Serviço Social no Brasil}

O ambiente vivido pela área de Serviço Social no contexto da criação do PPGPS favoreceu que se construísse, para aquele momento, uma proposta adequada aos interesses da área, ao quadro de professoras da UFMT e à própria instituição empenhada na criação de novos cursos stricto sensu, assim como à gestão do governo federal para a ampliação destes em nível nacional.

Dentre os novos cursos, é considerável a incidência em regiões tradicionalmente identificadas como periféricas, portanto, coerente com a interiorização pretendida pelo Plano Nacional de Pós-Graduação 2005-10. Foi o propósito de correção de desigualdades regionais e intrarregionais e de assimetrias entre áreas de conhecimento, previsto no PNPG 2005-10, que impulsionou o mestrado em Política Social, e outros programas da UFMT, que surgiram no período. ${ }^{2}$

2 Destaca-se inclusive que, na área de Serviço Social, o PPGPS é o segundo curso stricto sensu oferecido em uma instituição pública na região Centro-Oeste. 0 primeiro é o da Universidade de Brasília (UnB), mestrado e doutorado em Política Social, criado em 1990, sendo que a região ainda conta com o mestrado em Serviço Social da Pontifícia Universidade Católica de Goiás (PUC-GO), criado em 2007. Foram quase duas décadas para que se ampliasse a oferta da área na região, o que coloca o curso e a própria UFMT com uma responsabilidade 
Essas peculiaridades explicam a regularidade da demanda pelo curso, incluindo profissionais da região Norte, além de outros estados do Centro-Oeste, como Goiás e Mato Grosso do Sul, envolvendo, claro, todo o estado de Mato Grosso. Não se pode desprezar, inclusive, os fatores densidade demográfica e extensão territorial da região e do próprio estado, que, ao ofertar um curso de natureza pública, favorece a redução das dificuldades para acesso e permanência em programas de pós-graduação em outras localidades mais distantes do país.

Desde sua abertura, o PPGPS vem envidando esforços para se consolidar como referência regional na formação de profissionais que atuam, seja no ensino, pesquisa ou no ciclo das políticas públicas. A entrada da primeira turma em 2009 conferiu, assim, o início de implementação do curso, composta de doze profissionais com formação diversa na área das ciências humanas e sociais.

O programa, que em 2016 reviu seu projeto pedagógico inicial com o intuito de garantir melhor coerência entre área, linhas, disciplinas, assim como a articulação com os projetos de pesquisas das professoras e discentes, assenta-se na área de concentração "Política social, Estado, sociedade e direitos sociais" a qual, por sua vez, sustenta-se em duas linhas de pesquisa: Linha 1 - Política social e direitos sociais, cuja centralidade repousa sobre a política social e os determinantes econômicos e ideopolíticos de sua emergência e desenvolvimento. Aborda ainda os direitos sociais nos países capitalistas e a particularidade brasileira e regional, enfatizando o processo de luta e constituição de políticas públicas e sociais e suas implicações na garantia de direitos sociais. E a Linha 2 - Trabalho, questão social e Serviço Social, que desenvolve estudos sócio-históricos e ontológicos das categorias trabalho e questão social, a partir da configuração assumida na dinâmica da sociedade

significativa tanto no que se refere ao acesso à formação de mestres em política social, quanto ao potencial de contribuição na construção e disseminação do saber produzido para a sociedade e região. 
burguesa. Compreende, ainda, as determinações sociais da questão social no processo de formação social brasileiro, seus desafios históricos e implicações nos espaços sócio-ocupacionais e no exercício profissional dos(as) assistentes sociais e nas respostas produzidas ante demandas contemporâneas (UFMT, 2016).

As temáticas abordadas pelas linhas de pesquisa encontram-se relacionadas entre si e são coerentes com a área de concentração, refletindo sua vocação para a interdisciplinaridade, permitindo o diálogo entre as diferentes disciplinas que incidem nos modelos explicativos das políticas sociais. Neste sentido, a ênfase na interdisciplinaridade promove não apenas o debate, como colabora na compreensão de um conjunto de problemas e temas sob diferentes enfoques analíticos que as linhas de pesquisa se propõem a investigar, desenvolvendo reflexões teórico-metodológicas que recuperam questões e tensões que envolvem as políticas sociais e seus desdobramentos contemporâneos, garantindo espaços críticos de interlocução.

Nessa direção, o PPGPS, desde 2009, quando da entrada de sua primeira turma, até o final de 2019, formou 101 profissionais. As pesquisas orientadas pelas professoras das duas linhas de pesquisa resultam em dissertações que versam sobre as políticas sociais em suas diferentes dimensões, compreendendo as forças políticas e sociais de seu processo constitutivo e/ou em sua vinculação ao trabalho profissional.

A dinâmica da política social em sua construção, modelos e perfis de gestão, arena de conflitos de interesses em que forças e sujeitos sociais e políticos disputam sua direção, centraram a preocupação analítica das pesquisas desenvolvidas pelo seu corpo docente. A política social, como lócus em que ocorre a constituição de direitos e o reconhecimento da cidadania, constitui-se no campo no qual repousam os estudos realizados pelos três grupos de pesquisa do programa nessa primeira década, assim constituídos: 1) Política social, direitos sociais e Serviço Social; 2) Trabalho e sociabilidade e 3) Serviço Social e espaços sócio-ocupacionais. 


\subsection{A relevância social do PPGPS/UFMT no contexto regional}

A relação entre política e economia constitui-se no ethos que orienta toda a construção do percurso formativo desenvolvido pelo PPGPS, em que a política social guarda profunda identidade com os mecanismos de regulação estatal, mediados pelas diversas formas de participação e expressão dos movimentos sociais. E é esse ethos que tem atraído a diversidade profissional que marca a formação das turmas anualmente: economistas, administradores, historiadores, geógrafos, pedagogos, psicólogos, advogados, contadores e assistentes sociais, conforme o Gráfico 1.

Gráfico 1. Perfil de egressos por área de formação

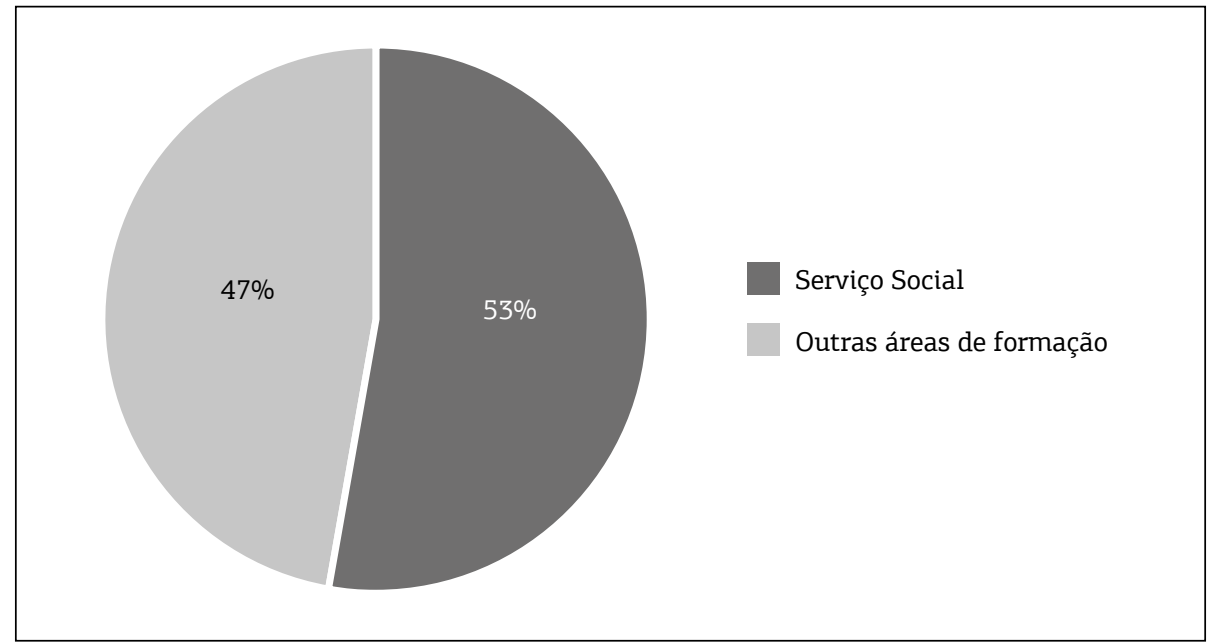

Fonte: Pesquisa direta.

Esse conjunto de profissionais possui fortes vínculos com as políticas sociais públicas em seu campo de atuação e/ou de interesse de pesquisa. Por isso, os propósitos do PPGPS de preparação, tanto para a intervenção qualificada para a pesquisa quanto para o ensino, respondem ainda a uma necessidade de diferentes perfis profissionais que pretendem aprimorar a atuação no campo das políticas públicas. Isso explica mais uma vez por 
que o programa é procurado e recebe profissionais que atuam no ensino público e privado, na gestão e implementação e, muito expressivamente, nos processos de formulação de políticas públicas, como demonstra o Gráfico 2 .

Gráfico 2. Perfil de egressos por área de atuação profissional

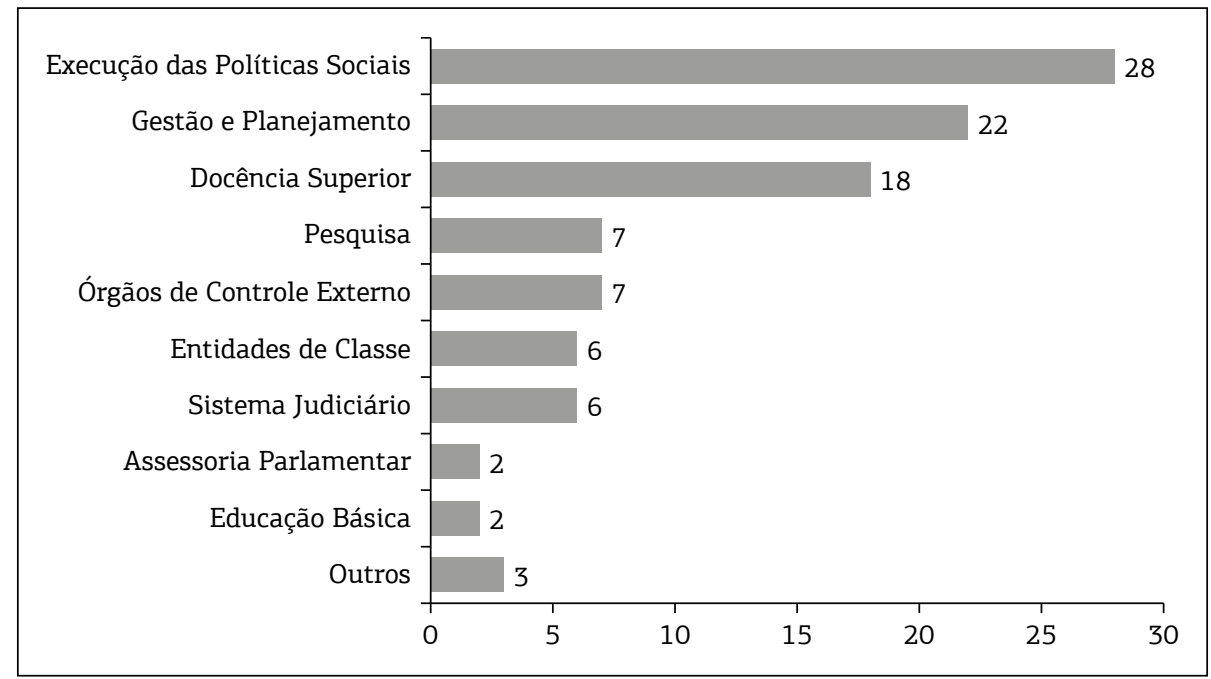

Fonte: Pesquisa direta.

Quanto ao perfil, esse público tem idade entre 23 e 45 anos, estando estes já inseridos em campos de atuação, e os mais jovens com inserção na docência no ensino superior e instituições de pesquisa. Desde 2009 os processos seletivos mantêm uma média de 58.83 candidatos para quinze vagas ofertadas. O programa vivencia, do mesmo modo, procura acentuada por matrículas na modalidade aluno especial, previsto na regulamentação geral da UFMT.

Em 2016, o PPGPS adere ao Programa de Qualificação Stricto Sensu dos Servidores Técnico-Administrativos em Educação da UFMT - PQSTAE, na modalidade sobrevaga, com o objetivo de contribuir no aprimoramento de práticas institucionais, com vistas à consolidação do ensino, pesquisa e extensão na universidade. 


\section{Tendências da produção do conhecimento do PPGPS/UFMT}

As temáticas eleitas pelos grupos de pesquisa do PPGPS evidenciam cuidado com a produção de informações e conhecimentos sobre a realidade regional e sua relação com as políticas públicas não redutíveis a espaços profissionais exigentes de atuação qualificada, mas, e principalmente, como campo de possibilidades assente na função pública do Estado em sua relação com a sociedade na garantia de direitos. Deve se salientar, ainda, que todos os projetos de pesquisa contam com a participação de discentes e docentes da graduação.

A propósito, é forte o vínculo entre graduação e pós-graduação, e o programa sempre pautou a condução de suas atividades valorizando esse vínculo desde o seu nascedouro. As professoras, assistentes sociais do quadro permanente, lecionam na graduação, orientam trabalhos de conclusão (TCs) e supervisionam bolsistas de extensão e de pesquisa, cujos resultados ampliam a produção técnica do PPGPS, como se vê a seguir.

Gráfico 3. Produção técnica em articulação com a graduação por ordem de maior recorrência

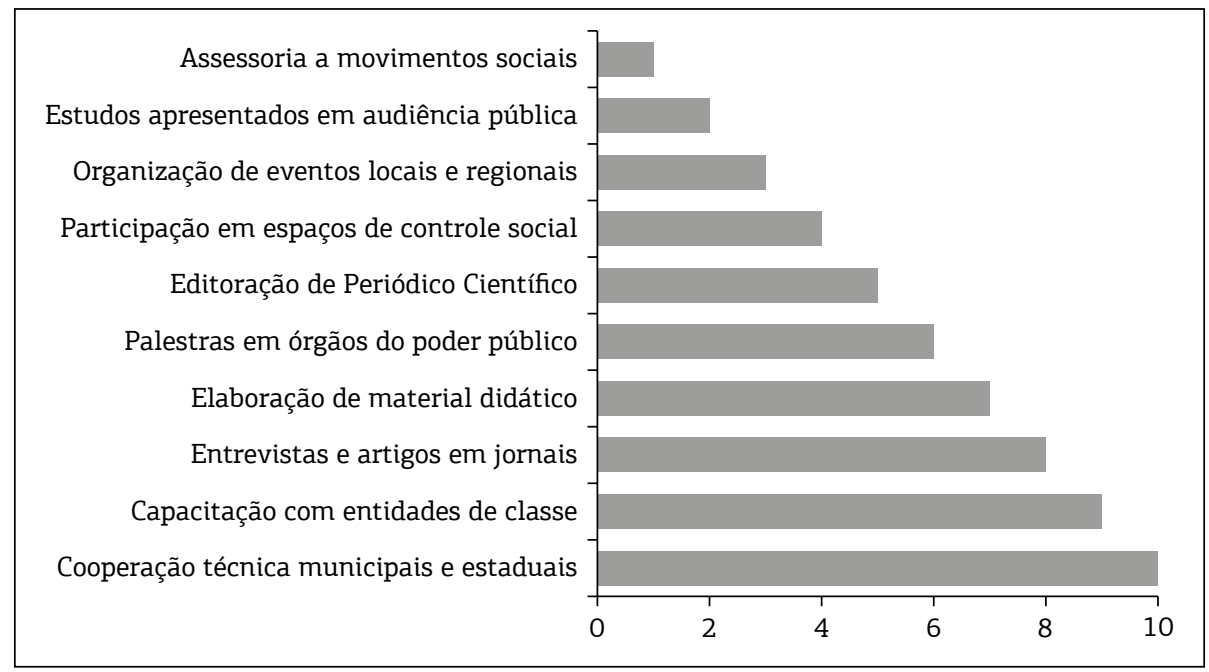

Fonte: Pesquisa direta. 
Seu cariz interdisciplinar, por se ocupar das políticas sociais, possibilita ao curso acolher profissionais das ciências sociais e humanas de perfis variados. Em todos os processos seletivos há a presença significativa de outras áreas além do próprio Serviço Social. Deve se destacar, ainda, que sua direção ético-política e teórico-metodológica constitui-se em fator atrativo de áreas afins a um curso da área de Serviço Social por ser o único da UFMT que apreende o conceito de política social que, sem desprezar os elementos racionais de sua institucionalidade burocrático-legal, a toma como resultante da tensa relação de interesses contraditórios sobre os quais erigem a sociedade capitalista.

Atentas à finalidade deste texto, foi realizado um levantamento da produção das 101 dissertações do PPGPS, observando ano de conclusão, tema do trabalho e sua vinculação com as áreas temáticas dos grupos temáticos de pesquisa (GTPs) da Abepss. Para tanto, foi necessário verificar os descritores, resumo e índice das dissertações para apurar com maior rigor as que podem se aproximar de mais de um GTP, situação constatada em diversas dissertações analisadas. Em alguns casos, elas possuem aproximação com até quatro GTPs. Assim, consideramos aspectos como ênfase do trabalho e a consonância com as ementas dos GTPs para mapeá-los em um único eixo.

Antes de lançarmos nossos apontamentos sobre a relação das dissertações com os GTPs da Abepss, destacamos que a compreensão sobre o significado da pesquisa e da produção do conhecimento está alicerçada nas bases dos valores defendidos pelo Projeto Ético-Político Profissional do Serviço Social (PEPP). Nesse sentido, entendemos a produção do conhecimento como um caminho imprescindível para a construção de alternativas críticas ao enfrentamento das contradições da sociabilidade burguesa, inclusive na direção estratégica da sua superação (Fortuna e Guedes, 2020).

No entanto, no quadro da emancipação política, a produção do conhecimento também deve "subsidiar a formulação de políticas sociais alternativas aos dogmas oficiais”, estreitar e retroalimentar a atuação das lutas sociais travadas pelos sujeitos coletivos, "assim como a consolidação de propostas profissionais que fortaleçam a ruptura com o conservadorismo e afirmem o compromisso com o trabalho, os direitos e a democracia" (Iamamoto, 2007, p. 452). 
Gráfico 4. Dissertações por área temática conforme GTPs da Abepss

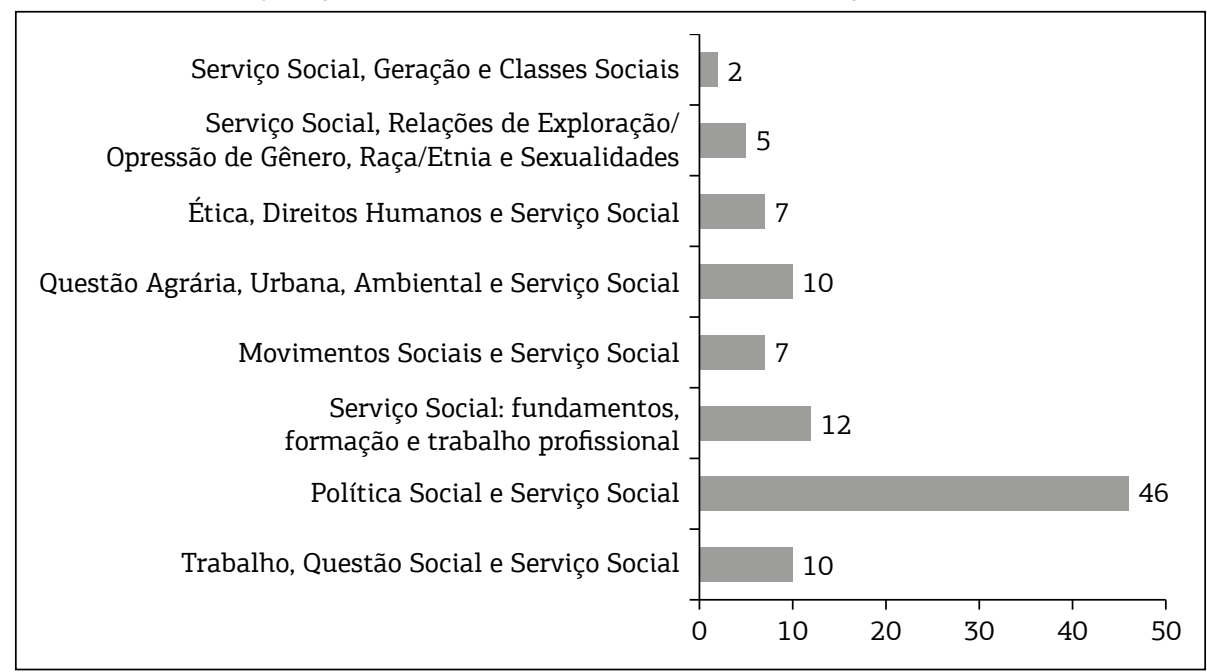

Fonte: Pesquisa direta.

As dissertações analisadas se localizam no campo democrático, e ainda que apontem o pluralismo ou a batalha de ideias, típica da tradição marxista, cabe ressaltar que neste texto não nos debruçamos para inquirir e quantificar o rigor das suas respectivas análises teóricas. A quantidade de dissertações alocadas no GTP de "Política social e Serviço Social" corresponde à quase a soma dos outros sete GTPs. Essa disparidade pode ser justificada pela natureza interdisciplinar dos estudos sobre política social, assim como pela diversidade de mestrandos(as) com formação em outras áreas, no período analisado.

O perfil da demanda para o PPGPS deve ser tratado como elemento que traz imbuído nessa busca o interesse pela política social, hipoteticamente "motivada pela busca do conhecimento crítico" (Mota, 2016, p. 171). Com doze dissertações, o GTP sobre "Fundamentos: formação e trabalho profissional” aparece na segunda colocação, confirmando um alinhamento com o que ocorre nos principais eventos científicos da categoria (Enpess e CBAS), em que a maioria dos trabalhos se concentra nos eixos temáticos de política social e de fundamentos. 
As tendências teóricas expressas pelas dissertações demonstram que, apesar da disparidade entre alguns dos GTPs, os oito estão contemplados. Esses dados servem também para orientar as futuras revisões do projeto pedagógico, com intuito de estreitar sua direção política com as novas e velhas demandas da região e potencializar sua inserção social.

\section{Considerações finais}

O exercício do estudo aqui apresentado constitui um ato de resistência aos ataques aos direitos da classe trabalhadora. Analisar criticamente esse tema, em tempos de retrocessos e censura generalizada, expressa a posição firme e explícita de defesa da educação, reivindicada no decorrer desses escritos. Assim, consideramos alcançados os objetivos propostos ao recompor e analisar o processo histórico dos dez anos do PPGPS/UFMT, trabalho este que não se esgota e que lança luzes para outros estudos.

Logo, ao analisarmos essa curta trajetória, acreditamos contribuir para o desvelamento das potências e fragilidades que nos envolvem. Não somente com o propósito de denunciar as ameaças concretas que estão colocadas pela gestão bolsonarista, mas, fundamentalmente, como elementos constituintes da bússola que nos orienta na defesa inflexível dos valores expressos em nosso PEPP, que, nessa conjuntura de desalento, nos impõem a tarefa de uma política real de solidariedade entre os programas de pós-graduação.

"Resistências requerem pedagogia crítica", nos alerta Leher (2019) ao insistir que investimento em pesquisa e a certeza da possibilidade de superação dessa história atual nos movimenta a reiterar nossa luta, em que "não cabem subterfúgios e hesitações. A democracia brasileira exige o melhor de nossa vontade e de nossa inteligência para fazer frente ao projeto autocrático que tenta se consolidar" (Idem, p. 205). Resgatar e redigir nossa história e memória é um passo fundamental para superar a exploração capitalista e as opressões que se reiteram em tempos de irracionalismos. 


\section{Referências}

FORTUNA, Sandra Lourenço de Andrade; GUEDES, Olegna de Souza. A produção do conhecimento e o projeto ético-político do serviço social. In: Revista Katálysis. v. 23, n. 1. Florianópolis: UFSC, 2020. Disponível em: https://periodicos.ufsc.br/index.php/katalysis/ article/view/1982-02592020v23n1p25/42508

IAMAMOTO, Marilda Villela. Serviço Social em tempo de capital fetiche: capital financeiro, trabalho e questão social. São Paulo: Cortez, 2007.

IASI, M.; FIGUEIREDO, I. M; NEVES, V. (Orgs.). A estratégia democrática popular: um inventário crítico. Marília: Lutas Anticapital, 2019.

LEHER, R. Autoritarismo contra a universidade: o desafio de popularizar a defesa da educação pública. São Paulo: Expressão Popular, 2019.

MÉSZÁROS, I. A educação para além do capital. São Paulo: Boitempo, 2008.

MOTA, Ana Elizabete. Serviço social brasileiro: insurgência intelectual e legado político. In: SILVA, Maria Liduína de Oliveira (Org.). Serviço social no Brasil: história de resistências e de ruptura com o conservadorismo. São Paulo: Cortez, 2016.

PINASSI, Maria O. A liberdade necessária e o tempo do verbo. In: PINASSI, Maria O. Da miséria ideológica à crise do capital: uma reconciliação histórica. São Paulo: Boitempo, 2009.

RAFAEL, J. C.; AZEVEDO, Eva Emilia Freire do Nascimento. Projetos de formação profissional em Serviço Social na UFM: o espaço da temática infância e adolescência. Revista Direitos, Trabalho e Política Social, Cuiabá, v. 5, n. 9, jul./dez. 2019.

UFMT. Projeto político pedagógico do curso de Serviço Social. Cuiabá: Departamento de Serviço Social, 2007.

UFMT. Projeto pedagógico do programa de pós-graduação em Política Social. Cuiabá: PPGPS, 2016.

\section{Sobre os autores}

Leana Oliveira Freitas - Doutora em Políticas Públicas; professora de Serviço Social e da pós-graduação em Política Social.

E-mail: leanaof@uol.com.br

Bruna Andrade Irineu - Doutora em Serviço Social; professora de Serviço Social e do programa de pós-graduação em Política Social.

E-mail: brunairineu@gmail.com

Josiley CARrijo RAFAel - Doutor em Serviço Social; professor de Serviço Social e da pós-graduação em Política Social.

E-mail: josileyrafael@yahoo.com.br 